\title{
APROXIMACIÓ A LES FONTS FISCALS DE LA CATALUNYA BAIXMEDIEVAL: LLIBRES D'ESTIMES, VALIES I MANIFESTS *
}

\author{
JORDI MORELLÓ I BAGET
}

\begin{abstract}
SUMARI
1. Introducció. - 2. Radiografia de la font. - 2.1. Els declarants: - 2.1.1. L'enunciat. - 2.1.2. La problemàtica existent al voltant dels focs. - 2.1.3. Exempts. - 2.2. Estructura interna: - 2.2.1. La determinació de la base imposable. - 2.2.2. Valoració de béns. - 2.2.3. Exempcions de béns. - Apèndix.
\end{abstract}

\section{INTRODUCCIÓ}

Tractarem en aquest article algunes qüestions concernents a un tipus de font -que genèricament denominarem «estimes»-, la qual es presenta en forma d'un inventari més o menys detallat de béns on és registrada la riquesa patrimonial d'una sèrie d'individus representatius en major o en menor grau del conjunt d'una població. Es tracta d'una font fiscal en tant que servia com a base per a fer reparticions d'impostos («talles») tenint en compte la riquesa de cadascú.

A Catalunya els primers exemplars conservats d'aquesta font es troben ja a partir de la primera meitat del segle XIV, encara que és ben possible que la seva aparició hagués tingut lloc abans. El tipus de font perdurà a l'edat moderna fins pràcticament al segle XVIII '. Contràriament al que hom pensava alguns

* Sigles utilitzades: $\mathrm{AHCC}=$ Arxiu Històric Comarcal de Cervera; $\mathrm{AHCM}=$ Arxiu Històric Comarcal de Manresa; $\mathrm{AHCR}=$ Arxiu Històric Comarcal de Reus; $\mathrm{AHCT}=$ Arxiu Històric Comarcal de Tàrrega; AHMA = Arxiu Històric Municipal d'Alcover; AHMI = Arxiu Històric Municipal d'Igualada.

' A l'Apèndix hem recollit algunes mostres dels segles XIV, XV i XVI per tal d'il.lustrar el que aquí exposarem. La nostra investigació, la qual forma part d'un programa més ampli. 
anys enrera, no som davant d'una font escadussera atès que aquesta és present en moltes localitats ', la qual cosa s' ha de posar en relació amb el desenvolupament general, similar pertot arreu, de la fiscalitat municipal. Encara que sobre això no es pot traçar una frontera entre la Catalunya Vella i la Nova, és en aquesta on les estimes, o similars, semblen haver tingut una major difusió.

Estimes, Valies o Manifests són els noms pels quals es coneix la font, uns noms variables segons el lloc o la zona on estiguem localitzats: Manifests a Cervera i a Manresa, Valies a Igualada, Estimes a Reus... '. Curiosament, en una mateixa àrea $i$ en localitats pròximes, $i$ fins $i$ tot veïnals, coexistiren diferents noms, com en el Camp de Tarragona ${ }^{4}$.

de recerca sobre la fiscalitat a la Corona d'Aragó sota la direcció del Prof. Manuel SÁNCHEZ, es centra primordialment en l'estudi de la fiscalitat dels municipis baixmedievals.

${ }^{2}$ Coneixem exemplars conservats a diversos llocs de la geografia catalana: Cervera, Manresa, Tàrrega, Igualada, Reus i Alcover, entre d'altres que aquí no tenim en compte; fins $i$ tot hi havia valies en llocs tan petits com a Montmaneu/La Panadella des dels anys 30 o 40 del segle XIV (vegeu Manuel SÁNCHEZ MARTÍNEZ, Entre el realengo y el señorío: un conflicto jurisdiccional entre Santes Creus y la "universitat" de Montmaneu/La Panadella (1382), dins Miscel.lània en bomenatge al P. Agusti Altisent, Tarragona, 1991, pp. 329-365). Es pot dir que la sèrie documental més rica es troba a Cervera: el primer exemplar conservat data del 1340 però no n'hi ha cap de complet fins al 1476, atès que a Cervera -com a Tàrrega- un «manifest» complet és el que es compon de quatre volums corresponents als quatre quarters, o barris, en què es dividia la ciutat. Per a l'àmbit cerverí és de referència obligada l'historiador Max TURULL, el qual sortirà reiteradament al llarg d'aquest article per les seves valuoses aportacions en moltes de les qüestions que aquí tractem (i a qui hem d'agrair el fet que ens hagi proporcionat material documental sobre els Manifests cerverins i manresans). Sobre Cervera cal esmentar d'aquest mateix autor: La configuració jurídica del municipi baix-medieval. Règim jurídic i fiscalitat a Cervera entre 1182-1430, Barcelona, 1990.

' Fora de Catalunya també hi ha diferents noms, alguns dels quals molt emparentats, referint-se al que en essència es tracta d'un mateix tipus de font: (a Occitània) estimes, compoix, vaillants i nommées; (a Itàlia) éstimi, catasti i libre; (a Castella) padrones de riqueza; (al País València) cappatrons; (i a Mallorca) stims. Per tenir una imatge global del que representa la font $\mathrm{i}$ quines són les direccions que pren la historiografia actual, sobretot a Itàlia i a França, cal remetre'ns a les Actes del Col.loqui de Saint-Cloud: J-L. BIGET/J.C. HERVÉ/Y. THÉBERT (ed.), Les cadastres anciens des villes et leur traitement par l'informatique. Actes de la table ronde organisée par le Centre d'bistoire urbaine de l'École normale supérieure de Saint-Cloud avec la collaboration de l'École franşaise de Rome et du Centre national de la recerche scientifique (Saint-Cloud, 31 janvier-2 février 1985), Rome, 1989.

${ }_{4}^{4}$ Els llibres conservats a Valls s'anomenen estimes com a Reus, a Riudoms manifests $i$, a la Selva del Camp, valies; a Tarragona, segons les referències indirectes que tenim, s'anomenaven manifests, però no se n'ha conservat cap. Pel que fa a Valls, tot i que encara no hem tingut ocasió d'examinar els exemplars dipositats a l'arxiu de la dita població (actualment en procés de reformes), sabem que compta amb un fons força ric; cfr. Fidel de 


\section{RADIOGRAFIA DE LA FONT}

En obrir un llibre d'estimes se sol trobar un preàmbul -en el cas que estigui complet- en el qual com a mínim es fan constar les persones encarregades de registrar els béns dels veïns, elegides per l'òrgan municipal, i la data de quan començà l'operació d'estimació. Aquestes comissions estaven formades per un major o un menor nombre de components, més o menys en consonància amb la grandària de la població '. En tot aquest afer era el mateix subjecte qui manifestava, denunciava o declarava els béns posseïts i els comissionats actuaven més aviat com a supervisors '. Tota declaració de béns constituiia, doncs, un acte públic i, en cas de malfiança o davant d'individus recalcitrants a declarar, els estimadors podien recórrer a les delacions dels veïns o procedir a taxacions d'ofici.

\subsection{Els declarants}

\subsubsection{L'enunciat}

En tot llibre d'estimes, hi ha una sèrie de dades referides als declarants. A continuació indiquem quines són:

MORAGAS I RODÉS, Catàleg dels llibres, pergamins i documents antics de l'arxiu municipal de la ciutat de Valls, Valls, 1916. Altrament, pel fet d'estar incomplets no sabem quin nom rebien a l'època els exemplars conservats a l'arxiu d'Alcover.

' A la ciutat de Cervera, al segle XIV, les comissions eren de vuit estimadors, dos per a cada quarter. A Tàrrega també eren dos estimadors per quarter. A la vila de Reus-localitat que hem estudiat bastant a fons-, bastaven, al segle XV, quatre o només dos estimadors i algunes vegades les comissions eren constituïdes per estimadors encarregats de registrar els béns ubicats a dins la vila $\mathrm{i}$ uns altres d'encarregats de registrar les terres del terme.

" El mateix terme «manifest» al.ludeix, òbviament, al fet de declarar o de denunciar els béns, declaració que es feia sota jurament (segrement) i davant notari o escrivà. A tot arreu es feien servir fórmules similars. Per exemple, a Manresa (làm. 4): coram dictis electis manifestavit omnia bona sua medio juramento ut sequitur, a Cervera (làm. 1) Berenguer de Cardona manifeste ab sagrament..., diu que ba...; a Alcover (làm. 7): Primo denuncia.... A les estimes de Tàrrega fins i tot s'indica la data en què es féu cada estimació (vegeu làm. 8). En altres estimes les anotacions són força lacòniques i es prescindeix de qualsevol formulisme. Es considera també la possibilitat de manifestar béns d'un altre, actuant en representació. Tenim un exemple d'això en el mateix Manifest de 1366 (làm. 1); citat ja per l'interessant treball de Max TURULL, La bacienda municipal y la tributación directa en Cataluña durante la Edad Media. Planteamiento general, «Revista de Hacienda Autonómica y Local» (Separata), XXII (1992), p. 59, n. 90. 
A. Els titulars de béns: el nom i el cognom de la persona que declara ? Una bona part dels declarants solen ser subjectes masculins, encara que, de manera menys assídua, també poden aparèixer algunes dones; sovint es fan servir fórmules referencials com «muller de» (seguit del nom del cònjuge difunt) ${ }^{8}$. Igualment, poden aparèixer registrats hereus (i també hereves), tots menors d'edat i portant el nom del transmissor de l'herència. Cal suposar que en aquests casos els tutors devien ser els encarregats de declarar els béns d'aquestes herències. En definitiva, tots els inscrits en aquests registres ho eren pel fet de ser posseïdors de béns.

Alguns enunciats són compostos, és a dir, subjectes amb acompanyants amb els quals es servava algun vincle de tipus familiar, si bé la presència d'aquests darrers sol ser testimonial ' . És bastant habitual trobar vídues acompanyades per fills menors d'edat dels quals aquestes podien ser tutores preferents; al contrari, és bastant rar trobar mullers declarant conjuntament amb els seus marits ${ }^{10}$.

Sigui com vulgui, no ens diuen pràcticament res sobre el que sempre roman en la foscor: la composició interna de les families ". Si, pel que fa a les

7 Algunes persones podien rebre un tractament especial amb la finalitat de fer ressaltar un status social, o categoria professional, mitjançant qualificatius com don, micer, mossèn, mestre...

${ }^{8}$ Tenim alguns exemples del primer tipus a la làm. 5 . No sempre podem estar segurs de la condició de viduittat; però algunes vegades l'enunciat ho deixa ben clar, com en el següent exemple extret de la làm. 4: Margarita, uxor Bernardi Palet, quondam.

9 I fins i tot anònima: A. Guiue sa mare, $G$. Ferrer e sa mare (làm. 5 ). Com es veu, no hi havia cap necessitat d'especificar el nom d'aquests subjectes secundaris.

${ }_{10}$ No obstant això, podem veure un cas de declaració conjunta marit/muller a la làm. 5. Fixem-nos, d'altra banda, que a la valia de la làm. 3 es fa referència al vestit d'ell e de sa muller, però com a titular de l'estima tan sols figura el marit, la qual cosa fa pensar que devia ser un fet relativament corrent la declaració de béns propis de la dona a nom del marit.

"La informació que es pot extreure de les estimes de Catalunya, tot $i$ tenir un gran interès per als estudis sobre demografia, és força limitada si la comparem amb les exhaustives informacions que subministren les estimes i els cadastres italians. En efecte, en alguns d'aquests s'especifica la composició interna de cada unitat familiar fent-hi constar, a més del cap de família, tots els membres que la integraven, consanguinis o no consanguinis, indicant també el sexe i l'edat, sovint de manera força precisa. Aquesta documentació ha permès realitzar estudis demogràfics molt exhaustius, com el prou conegut de David HeRLIHY i Christian KLAPISCH-ZUBER sobre el famós catasto de Florència (Les toscans et leur familles. Une étude du catasto de 1427, Paris, 1978). En una línia de recerca semblant podem citar Franca LEVEROTTI, La famiglia contadina lucchese all'inizio del '400, (Estratto) Edizioni Scientifique Italiane, pp. 235-268. A França es conserva un únic document -ens referim al cens de Carpentras de 1473- en el qual fou anotat el nombre de boques existents a cada foc; 
dones, normalment es tracta de vídues, pel que fa als homes és difícil saber si eren solters, casats o vidus.

B. Indicacions d'altra mena: esporàdicament apareixen indicacions referides a nexes familiars com «(tal), fill de...», «el gendre de (tal)», etc.; unes altres tenen per objecte diferenciar subjectes homònims: «major/menor de dies»; també poden aparèixer «àlias» $i$ indicacions d'origen o procedència. Tot i que són dades sempre útils per a intentar recompondre les relacions familiars $o$ d'altre índole entre els components d'una població, cal deixar clar que a través de les estimes de casa nostra estem limitadíssims.

C. Una altra indicació, també de caràcter complementari, és aquella que es refereix a les professions dels subjectes ${ }^{12}$. En general, els redactors d'estimes mostren poca predisposició a subministrar informació sobre les ocupacions dels declarants, fins al punt que sols esmenten alguns oficis o només els oficis d'alguns subjectes ${ }^{13}$.

Constituint apartats separats s'hi poden incloure habitants pertanyents a poblacions o llocs ubicats dins del terme de la ciutat o vila que dirigia l'Estima, la qual cosa té correspondència amb unes relacions de supeditació fiscal de les localitats petites a les grans ${ }^{14}$. A banda, podem trobar "forasters» o titulars foranis anotats per les propietats que tenien localitzades dins del terme ". De fet, a l'època no era gaire clar si l'impost havia de ser real (pagar pels béns i propietats que es posseïen en un lloc) o personal (pagar pel fet de ser veí d'un lloc) ${ }^{16}$.

seria, com deia R.H. BAUTIER, el «premier document de ce type qui soit signalé pour une ville française du moyen age»; Feux, population et structure sociale au milieu du XV: L'exemple de Carpentras, "Annales. Économies. Sociétés. Civilisations», XIV (1959), pp. 255-268.

12 En tenim alguns exemples a l'Apèndix, com a la làm. 5.

13 Això no obstant, també hi ha registres més generosos com el Manifest manresà de principis del segle XV, on trobem mencionats fins i tot «llauradors» (làms. 4-5), encara que aquest terme, sens dubte, no fa referència a la pagesia en sentit genèric sinó als pagesos més ben equipats: els possessors d'arades.

14 Coneixem els següents casos de llogarrets inclosos a les estimes dels llocs grans: Vergós de la Ribera (a Cervera); Vilanova del Camí (a Igualada); i, Castellvell i Almoster (a Reus).

15 Com a les estimes reusenques de 1445 , anotats al final de tot, o com a Tàrrega, on hi ha tot un volum dedicat a forasters, que normalment són de llocs propers com Vilagrassa.

${ }^{16}$ En realitat, darrera d'aquesta problemàtica planava una qüestió de tipus jurisdiccional. Estem, doncs, plenament d'acord amb Max TURULL que en el principi de jurisdiccio- 
Finalment, podem fins $\mathrm{i}$ tot trobar jueus anotats entre els restants declarants o a part, com en el llibre d'estimes de Balaguer de 1412, la qual cosa reflecteix el caràcter de "ghetto" que aquest grup social tenia a l'època".

\subsubsection{La problemàtica existent al voltant dels focs}

Aquest tipus de font planteja un problema cabdal per a la demografia i, de retop, per als estudis sobre fiscalitat, perquè els titulars de propietats no sempre eren coincidents amb els titulars de focs. Com és sabut, la condició indispensable per a considerar un foc com a tal era la domiciliació en una mateixa llar ${ }^{18}$. Això no obstant, a les estimes poden incloure's alguns focs desdoblats, és a dir, declarants que, tot $\mathrm{i}$ residir en una mateixa llar, eren anotats per separat. Podem assenyalar tres casos diferents de desdoblaments: a)entre marits $i$ mullers, quan aquestes declaraven béns dotals propis, o bé parafernals; b)entre pares i fills, en situacions creades arran de donacions inter vivos en el cas que l'hereu hagués rebut la herència del pare, el qual, tot i que es reservava l'usdefruit damunt dels béns cedits, retenia una determinada porció de béns pels quals podia continuar declarant en nom propi; i, finalment, c)entre mares vídues i fills majors d'edat que visquessin a la mateixa casa però declaressin a part ${ }^{19}$. Inversament, també hi podia haver persones d'una mateixa familia declarant junts malgrat viure en diferents domicilis.

nalitat devia convergir el caràcter real i personal de l'impost a l'hora de determinar quines persones i quins béns havien de contribuir en funció dels béns posseïts (vegeu La hacienda municipal..., p. 48).

17 Els jueus rebien un tracte diferent al dels cristians; vegeu, si no, l'estudi de Montserrat CASAS I NADAL, Els jueus de Balaguer en el Llibre de l'Estima de 1412, dins Actes del ler Col.loqui d'Història dels jueus a la Corona d'Aragó, Lleida, 1991, pp. 321-333. Segons informa aquesta autora, arran d'un pacte establert amb el municipi el 1382 els jueus quedaven obligats a contribuir per la meitat dels seus béns; del total dels béns taxats es feien dues parts iguals, una de les quals quedava exempta d'impostos (p. 323). No tan sols pagaven menys que els cristians, mercès a la reducció a la meitat en la determinació de les bases imposables, sinó també pels tipus de gravàmens que hom els imposava. En general, però, les comunitats jueves eren de competència exclusiva, en matèria fiscal, de la Corona.

18 focum autem intelligimus illum habere qui babet domicilium proprium in civitatem, castro vel villa (citat per Arlette HIGOUNET-NADAL, Les comptes de la taille et les sources de l'bistoire démographique de Périqueux au XIV siècle, Paris, 1965, p. 48, n. 6).

19 Del primer tipus indicat de desdoblament, en tenim un exemple a la làm. 2 entre uns cònjugues, ambdós possessors de béns propis. El més curiós és que inicialment era una 
Davant del relatiu control que podien exercir les autoritats municipals i els seus comissaris, cada cap de familía devia assajar estratègies per tal d'alleugerir el pes dels impostos o encaminades a aconseguir alguns avantatges fiscals, si bé el marge de maniobra devia ser major entre les famílies compostes (múltiples o extenses) que no pas entre les famílies simples (nuclears). A més, cal tenir en compte que les estructures familiars eren diferents en el medis urbans respecte dels rurals ${ }^{20}$. Així doncs, des del punt de vista de la fiscalitat, i no tan sols de la demografia, seria ideal conèixer la composició de les cèl.lules familiars en el moment de la realització d'unes estimes; així mateix, caldria conèixer a fons quines pautes intrafamiliars determinaven la via a seguir pel que fa als heretaments, l'emancipació dels fills i els canvis de domicili. Però, per damunt de tot, des del punt de vista dels historiadors de la fiscalitat cal conèixer com s'efectuava a cada localitat la repartició dels impostos. No oblidem, altrament, que estem tractant abans de res amb propietaris de béns i no amb focs $o$, si volem ser més precisos, amb propietaris i/o alhora possessors ${ }^{21}$.

\subsubsection{Exempts}

Qui no estava obligat a manifestar tampoc no estaria obligat a contribuir en cap talla ni real ni veïnal ${ }^{22}$. Se sap que arreu, davant la pressió de les

estimació comptada a nom únicament del subjecte masculí i que, per alguna raó que de moment desconeixem, més tard es varen comptar a banda els béns pertanyents a la dona, si bé sobre la mateixa estima. L'estimació global única, que era de 751 lliures, apareix anul.lada i desglossada en dues, allò que correspondria només al marit i allò que correspondria a la muller. El total estimat per a la dona, 210,5 lliures, suposa una part considerable de la quantitat que hi havia anotada inicialment.

20 Franca LEVEROTTI constata la diferenciació estructural de les famílies residents en medis rurals i urbans, respectivament (vegeu art. cit., p. 246). Pel que fa als medis rurals, és força interessant l'estudi de Maurice BERTHE, Fams i epidèmies al camp navarrès als segles XIV i XV, Barcelona, L'Avenç-SCEH, 1991.

${ }^{21}$ Davant dels tipus de declarants que ja hem indicat, podem trobar alguns enunciats atípics. Ens referim a les declaracions del tipus béns d'en Bernat Cunill (làm. 4). Aquests titulars es poden interpretar, com a mínim, de dues maneres diferents: com una manera de referir-se als béns d'un difunt que hagués quedat sense hereus, i que, per tant, no correspondria a cap realitat demogràfica; o bé referit a herències indivises en tant que els consorts que implicaven es trobarien estimats cadascú per la seva banda, segons les hipòtesis de JeanLouis BIGET, Les compoix d'Albi (XIV-XV siècles), dins Les cadastres anciens..., p. 107.

${ }^{22}$ No era el mateix estar exempt de manifestar i estar exempt de talles. La millor franquesa -com deia Max TURULL- era no haver de manifestar (La configuració jurídica..., p. 
autoritats municipals, el clergat (i en menor mesura la baixa noblesa) oposà tenaç resistència a contribuir en les talles que els municipis volien imposar-los. Sembla que ambdues parts havien arribat a solucions paccionades, variables a cada localitat: no declarar tots els béns, no contribuir en totes les talles, o, simplement, pagar menys que els altres. Les institucions eclesiàstiques van procurar rebre un tracte diferent per evitar caure sota la tutela de les universitats $\mathrm{i}$, quan finalment es conformaven a declarar, ho feien considerant que la seva contribució era un donatiu graciós i no pas una obligació onerosa ${ }^{23}$. A més, com se sap, aquestes institucions eren receptores de moltes rendes assignades a beneficis o a aniversaris que, vist el seu caire pietós, s'escapaven sempre dels registres d'estimes $i$, per consegüent, dels impostos municipals.

A banda dels esmentats, n'estaven també exempts els funcionaris reials i senyorials com, per exemple, els batlles ${ }^{24}$.

A l'extrem oposat als privilegiats hi havia els «miserables» els quals, si potser s'escapaven de l'estimació (i de les talles proporcionals a la riquesa), era en raó de la seva pobresa. De totes maneres, cal pensar que més aviat devien estar obligats a pagar capitacions de petites quantitats, la qual cosa sempre es deixava a l'arbitri dels estimadors ${ }^{25}$.

542). Evidentment, el problema de les exempcions afectava igual l'àmbit de les imposicions (impostos indirectes).

${ }^{23}$ Resulta molt clarificadora la declaració d'un manifest de Cervera a nom del convent de franciscans d'aquesta ciutat els quals al.legaven l'única raó per la qual es consideraven obligats a contribuir: bé saben vosaltres (...) com los eclesiàstics, frares menors de ley comuna be special, no porten manifest de la vila ni contreboexen en talles ni altres exactions ni són tenguts de manifestar sos béns ni almoynes ni beretats ni sensals sinó aquels los quals $j a$ ans que tinguessen poder per donació o altra via eren portats en manifest e talla per los donadós; tot seguit es feia relació dels béns "dignes» de contribució (aquest text es troba transcrit per Joan CANELA, Los Libros del «Manifest » de Cervera de 1476, tesi de llicenciatura inèdita, Barcelona, 1972, p. 175).

${ }^{24}$ Els batlles considerats naturals (sobre això, podeu veure Tomás LÓPEZ PIZCUETA, Sobre la percepción del "bovatge en el siglo XIV: una aportación al tema de la tasación directa en la Cataluña bajomedieval, dins Estudios sobre renta, fiscalidad y finanzas en la Cataluña bajomedieval (s.XII-XV), en premsa; Doc. $\mathrm{n}^{\circ}$ 5, cap. VI). Fora de Catalunya fins i tot podien estar exempts alguns magistrats municipals mentre durava l'exercici del seu càrrec ( $A$. HigOUNET-NADAL, ob. citm p. 51). A més a més, hi podia haver qui estigués obligat a contribuir només per algunes quantitats fixes en virtut de convenis personals, com en els pactes inclosos a Igualada en els mateixos llibres de valies i que són del tenor següent: És tengut lo dit mossèn en Joban contribuir en los càrrechs de la universitat per pacte fet e binit entre ell (e) la universitat cascun any XXI sous (AHMI Valies 1404).

29 Segons el Llibre de les Costums de Tortosa: A gent pobra deu pagar en lo comú sens tot contrast segons que.ls ciutadans ordenaran: en axí, però, que.s face ab raó (citat per Josep Maria FONT I RIUS, La administración financiera en los municipios medievales catalanes, dins Historia de la Hacienda española (épocas antigua y medieval), Madrid, 1982, p. 212). Cal dir que a les 
Altrament, és prou sabut que els municipis intentaven atraure pobladors, generalment individus qualificats amb determinats oficis, als quals es donaven facilitats a través de franqueses sobre totes o determinades contribucions ${ }^{26}$, encara que no sabriem dir fins a quin punt hom quedava també deslliurat de declarar béns. Atès que la condició de veïnatge anava estretament lligada al fet de contribuir en les talles del municipi, un cop extingit el període d'enfranquiment hom podria ser considerat ja com a veí de ple dret i passava a contribuir com tothom.

\subsection{Estructura interna}

\subsubsection{La determinació de la base imposable}

Com veurem seguidament el tipus d'estima pot variar a cada lloc en funció d'uns criteris, més simples o més elaborats, que reflecteixen uns estadis evolutius diferents pel que fa a la tècnica fiscal. Del conjunt de mostres que presentem a l'Apèndix, podem assenyalar procediments diferents segons la localitat:

1. Les estimes que es presenten com un simple llistat de béns (i de rendes) al final del qual s'anotava el valor corresponent a la suma de tots els béns avaluats pel seu valor real. Dins d'aquest grup situem les estimes de Reus (làms. 2/6/9), les d'Alcover (làm. 7) i les de Tàrrega (làm. 8). A Reus s'anoten en primer lloc els béns de tipus urbà i a continuació les terres. A Alcover, en canvi, les terres s'anoten primer i els béns urbans al final de tot. Sigui com vulgui, tant en un lloc com en un altre l'essencial de l'estima són les terres, de les quals es dóna un llistat força detallat (tipus de cultiu, ubicació, afrontacions...). A les de Tàrrega tan sols s'anoten béns immobles, primer les depen-

estimes occitanes es feia constar una categoria fiscal a banda, els anomenats nichils, de forma semblant als non babentes de les estimes italianes, és a dir, tots els qui no ultrapassaven un mínim de riquesa que el municipi mateix s'encarregava de fixar. A Catalunya, els més pobres o bé quedaven exclosos dels registres d'estimes o, malgrat tot, $s$ 'hi incloïen tot i declarar pocs béns i/o de poca vàlua. Respecte a la problemàtica dels miserables, vegeu M. TURULL, $L a$ bacienda municipal..., p. 49.

26 A part de les franqueses atorgades pels monarques per motius de rang, serveis prestats, etc. les quals afectaven només les exaccions que aquells imposaven a les viles del regne. 
dències urbanes $i$ tot seguit els diferents tipus de terres ${ }^{27}$. En suma, es tracta de registres molt simples. Això no obstant, a les estimes reusenques del 1445 apareixen algunes quantitats de deutes anotades separadament dels altres béns en previsió d'aplicar deduccions a les sumes del total, la qual cosa devia suposar un cert alleujament als deutors ${ }^{28}$. A les estimes d'Alcover, en canvi, es porten a terme deduccions de deutes sobre els béns mobles, si bé en cap moment no se sap quina quantitat hi és descomptada ${ }^{20}$. D'una manera o d'una altra, el fet de considerar certs «deutes» com a desgravació es podria concebre com una acció de justícia social -els pobres solen estar endeutats-, però cal pensar que podia igualment beneficiar els membres de les oligarquies municipals.

2. A les valies d'Igualada (vegeu làm. 3) es practicava un procediment menys simple. En aquest cas, al final del llistat de béns s'anoten els censals, la suma dels quals es descompta del total de la valia ${ }^{30}$. Per consegüent, poden aparèixer tres xifres globals diferents: en primer lloc, una valia «bruta» que és la suma simple de béns i que vindria a ser la base imposable; en segon lloc, la suma dels valors de censals que és el que es descompta; i, en tercer lloc, la valia neta, o sia, la base liquidable ${ }^{31}$.

$27 \mathrm{Al}$ començament de les estimes es declara: sie stat ordenat que totes e sengles persones que agen, tinguen e posehesquen posesions, ̧o és, alberchs, terres campes, vinyes e orts etc. (AHCT Estimes, fol. 1r). En efecte, es comprova que no hi és registrat cap tipus de bé moble.

${ }^{28}$ Vegeu làm. 5. Es pot comprovar que no és comptat ni descomptat del total. Aquestes deduccions no surten registrades en el mateix llibre però sabem que el Consell reusenc decidí aplicar deduccions de deutes en el transcurs del procés d'estimació realitzat el 1445.

29 En aquestes estimes és bastant freqüent trobar algun Item lo moble dedubits los deutes (làm. 7) i també es podien fer deduccions sobre el valor del bestiar. A les estimes de Reus (1445) tenim expressions com llevat lo sens (làm. 7), referides a albergs $i$ altres immobles urbans, les quals pressuposen un còmput de la renda per tal de deduir-la sobre el bé declarat. Tampoc aquí no s'indica quant muntava el cens, la qual cosa ens priva de saber quin era el valor real del bé en qüestió.

${ }^{30}$ Les fórmules utilitzades són totes semblants: dix que deu de què fa sensal, mentre que en els muntants globals s'utilitza la següent expressió: En la vàlua de què deu pagar abatuts deutes (làm. 3). Cal tenir en compte que, des de la part del censalista i del creditor, censals i deutes figuren com a capital comptat en la valoració positiva de béns. Tal com es deia a Florència: "Quello sia messo al incarico al debitore è messo a substantia al creditore» (Cfr. D. Herlihy/Ch. KLAPISCH-ZUber, Les toscans..., p. 69, n. 72).

${ }^{31}$ En l'exemple que tenim només hi ha indicat això últim: la valia neta. En altres valies del mateix llibre figuren els tres valors indicats: «suma de valia/suma de censals/valia neta». Retornant a l'exemple de la làmina, podem veure que la valia bruta suma 187,5 lliures, els censals $30 \mathrm{ll}$., i la valia neta queda reduïda a 157,5 ll. Es tracta d'un cas de deducció íntegra, però no sempre es dóna una coincidència entre el muntant dels censals i la deducció aplicada. 
Així doncs, aquest mètode consistia a desgravar els valors dels censals (suposadament capitalitzats) del total estimat. Cal donar un sentit ampli a la noció de "deutes», dins dels quals podien quedar inclosos tant els deutes pròpiament dits (estimes de Reus/Alcover) com les càrregues dels censals morts, com acabem de veure-ho (valies d'Igualada). Les deduccions, per tant, es podien fer sobre el total o sobre una determinada categoria de béns, i per mitjà de deduccions íntegres o bé parcials".

$\mathrm{Al}$ marge de tot això, s'observa que sovint els destinataris d'aquests censals eren institucions eclesiàstiques; una sola ullada a les esmentades valies és suficient per adonar-se de fins a quin punt les institucions eclesiàstiques acaparaven censals.

3. Als Manifests cerverins, les valoracions globals de béns es desglossen en dues xifres corresponents a la suma dels béns mobles, per un costat, i a la dels béns immobles, per un altre. Com diu Max TURULL, es tractava d'una base imposable doble "3i més no, a l'hora de repartir una talla el consell d'aquest municipi taxava el moble diferentment de l'immoble de manera que el tipus de gravamen aplicat als béns mobles era més carregós - normalment el doble- que l'aplicat als immobles ${ }^{34}$. Aquesta desigual taxació té una explicació lògica si pensem en la major dificultat $\mathrm{o}$ incapacitat dels agents municipals per conèixer la veritable riquesa moble de cada veí sobre els quals planava una possibilitat major de frau ${ }^{35}$. Però aquest procediment comportava un problema com era el fet de marcar una frontera entre els béns mobles i els immobles, la qual cosa no sempre quedava clara (sobretot pel que fa als censals morts). A Cervera sovintejaren les discusions al voltant d'aquesta qüestió ${ }^{36}$. Naturalment, aquests debats eren inexistents on no es practicava una taxació doble de béns.

32 Sobre el tema de les deduccions, podeu veure Albert RIGAUDIÈRE, Connaissance, composition et estimation du moble à travers $d u$ quelques livres d'Estimes du Midi français (XIV-XV siècles), dins Les cadastres anciens..., pp. 76 i ss.).

34 La hacienda municipal..., p. 61.

${ }^{34}$ Taxant, per exemple, el moble a $6 \mathrm{~s}$. $2 \mathrm{~d}$. i el siti a la meitat de l'anterior (citat per M. TURUll, La hacienda municipal..., p. 71, n. 115).

3) Sobre aquesta problemàtica, vegeu A. RigAUDIÈRE, art. cit., pp. 41-81. En ciutats de certa categoria, on les activitats estaven més desenvolupades i diversificades, la riquesa moble tenia un major pes específic tot i que mai no arribaria a representar un percentage destacat en comparació amb la immoble, com ho demostren Max TURULL i Jaume Ribalta per al cas cerverí -a partir de les múltiples dades extretes de la sèrie de manifests del segle XIV-, ja que, segons els seus càlculs, la immoble venia a representar el $80 \%$ de la riquesa total (Diferenciació social i distribució social de l'espai urbà en la Catalunya baix-medieval (Cervera, 1340-1382). Ciutat i poder social en el feudalisme declinant, en premsa, pp. 32- 33).

${ }^{36}$ I d'altres al voltant de si havia de ser manifestat el capital o la renda del censal. 
4. A Manresa se seguia un procediment més elaborat, probablement el més elaborat en l'àmbit de tot Catalunya.

a) En un primer llistat (vegeu làm. 4) apareix una relació simple i pura de béns, com en els anteriors exemples, però optant per un mètode diferent al dels manifests cerverins, tot i que el resultat n'era el mateix. Pel que fa als béns immobles, s'anota tant el valor real com la meitat d'aquest valor; en canvi, es manté íntegre el valor dels béns considerats com a mobles ${ }^{37}$. Així donçs, els manifests de Manresa es diferencien dels de Cervera en aquesta reducció operada a la base en el $50 \%$ del valor d'alguns béns mobles ${ }^{38}$.

b) En un segon llistat molt més sumari, ja que només registra els noms dels subjectes i no els béns (làm. 5), es donen tres xifres a través d'unes operacions de les quals ara per ara desconeixem el mecanisme mitjançant el qual s'obtenien. Una primera xifra pot ser la suma global de la valoració de cada subjecte havent ja realitzat les pertinents reduccions; una altra xifra sembla representar un percentatge respecte a la primera que cal suposar força variable, a l'entorn potser d'un $10 \%$; i, finalment, s'anoten algunes quantitats mínimes derivades de les anteriors, probablement utilitzant alguna escala de valors. Però, insistim, està encara per desxifrar la tècnica exacta que es fa servir en aquests Manifests ${ }^{39}$.

Amb tot, el procediment emprat en la determinació de la base és prou definitori com per considerar-lo gairebé equiparable, sinó del tot, amb certs procediments practicats enllà dels Pirineus i que reben el nom d'alliurament. ${ }^{40}$.

Totes aquestes discussions serviren, almenys al segle XIV, de plataforma de confrontació política entre sectors socials diferents (sobre això M. TURULL, La configuració jurídica..., pp. 470-71).

37 Val la pena detallar quins béns es consideraven mobles: diners, deutes, argent, bestiar, blat, oli, esclaus, etc.; i com a béns immobles figuren els següents: vexells vinaders, vestit, roba i moble de casa... (en dóna raó M. TURULL, La hacienda municipal..., p. 39, n. 50). Com es veu, es tracta d'una distinció bastant relativa i si més no selectiva. L'aplicació d'una reducció no respon tant al fet de pertànyer a una categoria o a una altra (una distinció que era poc clara en alguns casos) sinó més aviat al fet de considerar un bé com a bàsic o no per al sosteniment d'una família.

${ }_{38}$ A banda, trobem també algunes consignacions de deutes anotats separadament de les restants estimacions que o bé es devien descomptar del total o bé es deixaven com un descompte opcional.

39 De totes maneres, pel que respecte a aquests Manifests ens remetem als comentaris de M. TURULl, La bacienda municipal..., p. 68, n. 107.

40 En canvi, si ens cenyim a la classificació que en dóna Max TURULL, cap dels casos estudiats no es desmarcaria del que seria una única modalitat d'estimes; La hacienda municipal..., pp. 60-61. Les altres dues modalitats eren, en segon lloc, el sistema de l'alliurament que es practicava, per exemple, al Llenguadoc (s'ignoren, en alguns casos, quins 


\subsubsection{Valoració de béns}

Atesa la brevetat d'aquest article, no podem entretenir-nos a comentar la variada tipologia de béns que apareixen registrats en els llibres d'estimes. Ara per ara, la qüestió que ens interessa tractar és com eren avaluats els diferents tipus de béns.

Els subjectes declaraven no tan sols els béns posseïts sinó també el seu valor (estimació directa) ${ }^{41}$, encara que també podia fer-se una estimació a partir de la comprovació en anteriors estimes (estimació indirecta) o a partir també de l'aplicació de certs barems (estimació objectiva) ${ }^{12}$.

Les vàlues es fixaven en moneda de compte (lliures/sous/ diners) ${ }^{43}$. Per als béns immobles es tractava d'una valoració real (o de mercat) -si és que no hi interferien deduccions sobre el bé valorat-, o teòrica quan es tractava de béns que tinguessin poca presència en els circuits del mercat. Això no obstant, no s'ha de creure que existís una identificació absoluta entre, d'una banda, el valor d'estimació i, d'una altra, el valor mercantil (preu) ${ }^{\text {t4 }}$.

càlculs es realitzaven per arribar a obtenir de cada bé uns valors força baixos que poc tenien a veure amb els valors reals); com a tercera modalitat el dit autor es refereix al sistema del catasto que veiem concretat en el de Florència de 1427 (en aquest cas, els càlculs efectuats en l'obtenció de quotes contributives ja no eren resultat únicament dels valors d'estimació ja que tenien en compte unes altres variables).

${ }^{41}$ A Cervera tenim el cas curiós d'un manifestant que no sabia quant podia valer l'arrendament d'una escrivania que era propietat del rei (làm. 2): Item manifesta e dix que lo dit $P$. de Cardona ba la scrivania del veguer de Cervera per com cessió del senyor rey avida del dit $P$. de Cardona e de mi, dit Berenguer de Cardona, fiyll seu, a la qual no posse preu per tal com ignore e no pot saber el temps que ha a venir los emoluments d'aquella quals seran ni quant poran valer, etc. afegint-hi que no entenia per què havia de contribuir per la dita escrivania essent com era propietat del rei $\mathrm{i}$ atès que mai cap dels seus predecessors no hi havia contribuït.

${ }^{42}$ Els tres tipus d'estimació (directa/indirecta/objectiva) es troben convenientment explicats per M. TURULL, La hacienda municipal..., p. 62. A Cervera tenim el cas curiós d'un manifestant que no sabia quant podia valer l'arrendament d'una escrivania que era propietat del rei (làm. 2): Item manifesta e dix que lo dit $P$. de Cardona ha la scrivania del veguer de Cervera per com cessió del senyor rey avida del dit $P$. de Cardona e de mi, dit Berenguer de Cardona, fiyll seu, a la qual no posse preu per tal com ignore e no pot saber el temps que ba a venir los emoluments d'aquella quals seran ni quant poran valer, etc. afegint-hi que no entenia per què havia de contribuir per la dita escrivania essent com era propietat del rei i atès que mai cap dels seus predecessors no hi havia contribuït.

43. En els manifests de Cervera (s. XIV) la valoració es feia només en sous, per una raó simple, i és que d'aquesta manera l'aplicació d'un gravamen, fos quin fos, seria més còmoda $\mathrm{i}$ ràpida segons M. TURULL, La hacienda municipal..., p. 60.

${ }^{44}$ Una de les ordinacions municipals de Perugia prescrivia que, en el moment d'anotar la vàlua, s'havia de posar el preu si aquest era més alt que l'estimació $i$, viceversa, s'havia de posar l'estimació tal qual si aquesta resultava major que el preu (Cfr. Alberto Grohman, Città e territorio tra Medioevo ed Età Moderna, II, Perugia, 1981, p. 1035). 
Cal suposar que en l'estimació de les terres es devien tenir en compte diversos factors, però que n'hi havia dos d'especialment determinants: la superfície o la grandària de la peça de terra i el tipus de conreu ${ }^{45}$. Els lloguers de les cases, les pensions dels censals morts, els censos de les terres... es podien capitalitzar mitjançant l'aplicació d'un determinat coeficient considerant que representaven un tant per cent del valor real ${ }^{4}$. En l'avaluació dels arrendaments es tenia en compte el preu i el temps ${ }^{47}$. Les vàlues de certs productes agrícoles (blat, vi, oli, safrà, etc.) i del bestiar s'obtenien a partir d'uns «fors» o barems prefixats ${ }^{48}$. Els estimadors, per consegüent, havien d'anar proveïts amb taules d'equivalències, el declarant manifestava la quantitat posseïda d'un producte i l'estimador en deduïa el valor corresponent ${ }^{49}$. Semblantment, els recipients també devien ser valorats a partir de certes mesures de capacitat ${ }^{30}$.

45 Altres factors: el tipus de sòl, la localització i la distància al nucli urbà, i els censos (si es tractava d'una possessió emfitèutica).

${ }^{46}$ En anotacions de béns com diners lo cabal de què rep XXXV s. de censal.......XXXV s. (AHCR Estimes 1445) és clar que la valoració era d'un 5\%. En relació amb el bovatge, s'establia que els lloguers de les cases i dels obradors es farien estimar al 10\% (Cfr. T. LÓPEZ, art. cit., Doc. $\mathrm{n}^{\circ} 1$ i 3). Jean-Louis BIGET creu que generalment el coeficient aplicat a una renda, almenys als orígens, fóra 10 , considerant que la renda representava el $10 \%$ del capital (art. cit., p. 111). Albert RIGAUDIÈRE considera que s'aplicaven dues taxes diferents segons es tractés de «rentes constituées» damunt dels immobles urbans $(6,25 \%)$ o de rendes $(5 \%)$. Aquesta diferència s'explica, segons el mateix autor, "par la pratique qui veut que, dans le droit des rentes, le taux de capitalisation des rentes constituées soit toujours supérieur à celui des rentes de bail d'héritage" (art. cit., p. 73). En el catasto florentí de 1427 es capitalitzaren les rendes de les terres al 7\% (D. HeRLIHY/Ch. KLAPISCH-ZubER, Les toscans..., p. 65). A Perugia, el 1436, s'establí que els lloguers de les cases fossin estimats segons la localització de manera que, depenent d'això, 5, 6 o 7 lliures del preu del lloguer es podien fer correspondre a una estimació igual de 100 lliures (A. GroHmAN, ob. cit., I, p. 138).

${ }_{47}$ Com en el següent exemple que ens proporciona un manifest cerverí: Item lo dit Anthoni comprà e arrendà a IX anys les rendes del feu d'en Guillem za Corbella, castlà de la Guàrdia Lada, per preu de MMDCCC sol. e los dits anys són passats exceptats III anys sdevenidors per los quals ba reebre e tenir lo dit feu e rendes, e fa per ayn CCCXI sol. Eaxifan en suma......DCCCCXXXIII sol.; extret de M. TURULL, Antoni Toldrà (notari del segle XIV) i la "Summa Rolandina», "Miscel.lània Cerverina», VI (1988), p. 49. Com es pot veure, es taxava el que es rebria durant els tres anys que mancaven per a complir el termini estipulat fins a nou, és a dir, les 3/9 parts del preu de l'arrendament.

${ }_{48}$ Era important, doncs, declarar les quantitats de cada producte: forment 111 quarteres; vinum VII sesters (làm. 3); X mitgeres de forment; un muig de vi (làm. 1/bis).

49 En aquesta mena d'estimacions objectives devien aplicar-se criteris de taxació semblants als que coneixem per al cas dels bovatges, és a dir, els manifestants estaven obligats a declarar les quantitats de tot allò que posseïen (diners, pans, safrà, etc.) i els bovaters (estimadors) havien de deduir els valors d'aquelles quantitats a partir d'uns barems (Cfr. T. LópeZ, art. cit., Doc. $\mathrm{n}^{\circ} 4$, cap. V).

so Com a les indicades a les valies igualadines: vexels una cova de VII sesters/altre de VIII sesters... (làm. 3). 


\subsubsection{Exempcions de béns}

No tots els béns calia que fossin manifestats i/o taxats. En això no sabem fins a quin punt cada municipi va actuar pel seu compte o bé si va haver-hi una certa uniformització de criteris i de pautes comunament acceptades a tot arreu. La qüestió era no malmetre la capacitat productiva de les famílies en tot allò que pogués considerar-se com a bàsic per al seu sosteniment. Una manera de posar en pràctica aquest principi era, pel que fa als béns mobles, considerant tan sols els excedents.

De totes maneres, saber quins béns podien estar exclosos d'estimació no és una tasca gaire facil per a l'investigador: el caràcter globalitzador o indeterminat d'alguns enunciats no hi ajuda gens ni mica. És poc probable que es declarés tot el moble que hi havia a les cases, entès el tot com a inclusió d'objectes d'ínfim valor i d'utilitat domèstica ". Sembla que el bestiar utilitzat com a instrument de treball es deixava de banda i es declarava, en canvi, aquell que era objecte de negoci. Almenys pel que fa als productes agrícoles, es descomptava tot allò considerat necessari per al proveïment domèstic (tant per a l'autoconsum com per a la reproducció) ${ }^{{ }^{2}}$; cal preguntar-se, aleshores, on es fixava el límit del que es considerava com a provisió? i, també, a partir de quin límit, l'excedent? ". I, pel que fa als recipients, cal suposar que només es devien tenir en compte aquells que contenien excedents després d'apartar els que contenien queviures ". Resumint, quedarien exempts tots aquells béns que no

"Pel que fa al bovatge, es diu ben clar que els utensilis domèstics quedaven tots exempts excepte aquells que fossin tinguts com a causa negociacionis, conduccionis vel lucri (Cfr. T. LÓPEZ, art. cit., Doc. n" 4, cap. X). Es tenia especial cura de consignar objectes de valor, com, posem per cas, les tres culleres d'argent que apareixen a la làmina 3 .

52 Tant del blat com del vi calia deduir, de cara al pagament del bovatge, tot allò que durant l'any fos necessari sive in comestione sive in semine terre (Cfr. T. LÓPEZ, art. cit., Doc. $\mathrm{n}^{\prime \prime}$ 4, cap. XI).

${ }^{33}$ En aquesta qüestió, la font no acostuma a fer gaires precisions. Algunes vegades podem trobar, si més no, interessants informacions, com en els manifests de Cervera (làm. 1/bis): Item diu que ha X migeres de forment les quals presse CX sols. e an mester en provessió de son alberch $X L$ o $L$ migeres. Més explícit és el següent exemple: Item diu que ha forment, go és saber $L X$ migeres que stime a rabó de XI sols. per migera, del qual requer que li sie levada provissió e per sembrar aytant com n.a mester e just sie (text transcrit per M. TURULL, Antoni Toldrà..., pp. 47-51). Efectivament, els 660 sous, que podien constituir la vàlua completa d'aquelles seixanta mitgeres, quedaven reduïts a 600 sous; aquesta diferència suposa que es consideraven necessàries com a provisió i com a llavor entre 5 i 6 mitgeres (anuals?).

${ }^{34}$ Segons una de les prescripcions establertes per al pagament del bovatge, els recipients que servien per a la conservació dels productes de collita pròpia en quedaven exempts, però no hi quedaven si contenien productes destinats a la venda (Cfr. T. LÓPEZ, art. cit., Doc. $\mathrm{n}^{\circ} 4$, cap. IV). 
reportessin al propietari uns beneficis o, plantejat al revés, es tindria en compte preferentment tot allò que era objecte de comercialització o d'ostentació de riquesa.

Resumint, hem començant fent un esbós de tipus descriptiu sobre un tipus de font, les estimes, i hem acabat comentant algunes de les qüestions que aquestes ens plantegen tenint en compte les característiques internes dels exemplars utilitzats. D'aquesta manera hem pogut constatar la diversitat de procediments practicats a cada localitat pel que respecte a la determinació de les bases imposables $\mathrm{i} / \mathrm{o}$ liquidables sobre les quals es taxava posteriorment l'impost.

Tanmateix, som en una fase inicial de la investigació. En un futur no gaire llunyà esperem operar amb un ventall documental més ampli, adjuntant-hi estimes d'altres localitats, la qual cosa ens permetrà completar i perfeccionar l'esquema actual sobre les modalitats de la font. Per aquesta via esperem arribar a un millor coneixement de la fiscalitat municipal a Catalunya en època medieval.

\section{RÉSUMÉ}

L'article constitue une brève exégèse du type de source fiscale, qui reçoit différents noms en Catalogne, noms que l'on trouvera dans le titre même.

En prenant comme exemples des extraits de sources appartenant aux archives municipales catalanes (Appendice), l'auteur réalise une description sommaire de la source en même temps qu'il met en évidence, dans chacun des cas, les différents procédés employés pour l'assiette de l'impôt. Il fait tout spécialement ressortir les divers aspects et problèmes que représentent la dite source, en tenant compte de l'historiographie étrangère, en particulier la franco-italienne, qui établit son étude sur similaire documentation.

\section{SUMMARY}

The article constitutes a brief exegesis of the kind of fiscal sources that receives different names in Catalonia, names that are listed in this very title. 
Taking as an example the extracts of the sources belonging to the Catalan municipal archives (Appendix), the author realises a summary description of the source whilst he puts in evidence, in every case separately, the different processes used to determinate the base of the taxes. He focuses very specially his attention on several aspects and problems that represent this source, taking in consideration foreign historiography, in particular, the franco-italian.

\section{APÈNDIX:}

Índex de làmines:

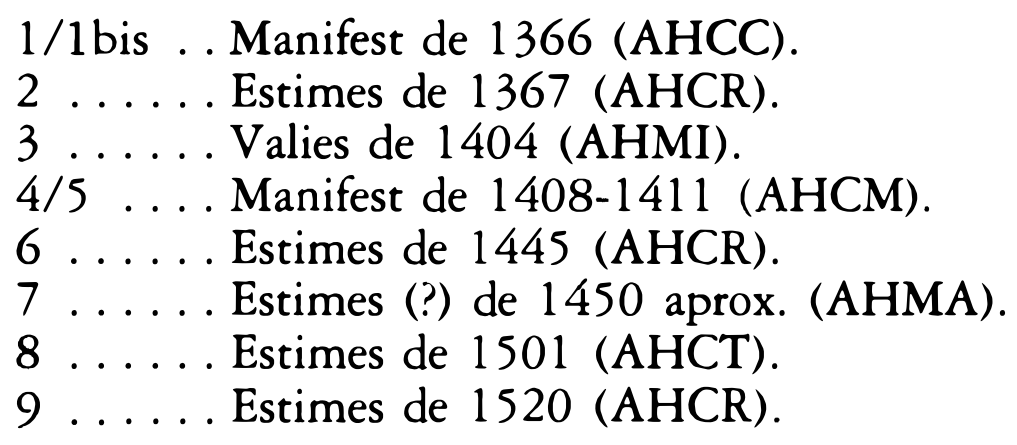

